\title{
Coexistence of macular corneal dystrophy types I and II in a single sibship
}

Ning-Pu Liu, Jennifer Baldwin, Felicia Lennon, Jeffrey M Stajich, Eugene J-M A Thonar, Margaret A Pericak-Vance, Gordon K Klintworth, Jeffery M Vance

\begin{abstract}
Background-Macular corneal dystrophy (MCD) is an inherited autosomal recessive disorder that has been subdivided into two primary immunophenotypes, MCD types I and II. The MCD type I gene has been localised previously to chromosome 16q22 and suggestive evidence provided that MCD type II gene is also linked to this region. Here an unusual family is reported where both MCD types I and II are found in a single sibship.

Methods-Immunoreactivity to an antikeratan sulphate monoclonal antibody (5-D-4) was evaluated in patients' serum and in corneal tissue obtained at keratoplasty. Chromosomal haplotypes were constructed using microsatellite repeat markers spanning the region of the MCD type I locus.

Results-Immunological studies demonstrated that two of the affected siblings have MCD type II while one has MCD type I. Haplotype analysis suggests that all three affected sibs inherited one identical parental haplotype. However, the two MCD types differ in their alternative chromosome with both MCD type II children sharing an identical haplotype, different from their MCD type I sibling.

Conclusion-The findings in this study support the hypothesis that the genes for MCD types I and II co-localise to the same region of chromosome 16 and are likely to be due to allelic manifestations of the same abnormal gene.

(Br F Ophthalmol 1998;82:241-244)
\end{abstract}

Macular corneal dystrophy (MCD) is an autosomal recessive disorder that comprises 10 $75 \%$ of the corneal dystrophies requiring penetrating keratoplasty, depending on the population. ${ }^{1-3}$ Patients develop irregular, cloudy regions that begin axially in both corneas. These areas progressively merge until eventually the entire corneal stroma opacifies. Immunological evaluation of antigenic keratan sulphate (AgKS) in serum and corneal tissue has shown that cases of MCD can be subdivided into two basic immunophenotypes. ${ }^{4}$ In MCD type I, AgKS immunoreactivity is absent from both serum and corneal tissue. Detectable, and often normal, serum AgKS levels and corneal accumulations that react with a monoclonal anti-keratan sulphate (KS) antibody characterise MCD type II. ${ }^{4}$ Recently, MCD type IA, an additional subclass of immunoreactivity, has been de- scribed in families from Saudi Arabia. ${ }^{5}$ In these individuals, AgKS immunoreactivity is absent from both serum and corneal stroma, but accumulations within the keratocytes react with the anti-KS antibody.

In a previous linkage study, we localised the MCD type I locus to chromosome $16 \mathrm{q} 22 .{ }^{6}$ Analysis of several MCD type II families provided a maximum lod score of $\mathrm{Zmax}=2.5$ to the chromosome 16 microsatellite D16S518, one of the flanking markers for MCD type I. In that report, as well as in the one of Jonasson and colleagues, ${ }^{2}$ patients with both MCD type I and MCD type II were observed in a large 15 generation pedigree. However, none was observed in the same sibship and a chance occurrence could not be excluded.

Here, we report the finding of both MCD type I and type II individuals in a single sibship of an American family. Together, these findings provide support for the hypothesis that these antigenically different forms of MCD may be due to defects in the same genetic locus.

\section{Materials and methods}

After obtaining informed consent from participants, venepuncture was used to collect blood for DNA and AgKS analysis. ${ }^{7-9}$ The serum levels of AgKS were determined using a well established enzyme linked immunosorbent assay (ELISA) and an anti-KS monoclonal antibody (5-D-4) (ICN Biomedical) directed against a highly sulphated epitope present on KS chains. ${ }^{9}$ The immunohistochemical evaluation of the excised corneal tissue used the same antibody on pathological corneal tissue. ${ }^{4}$

For haplotype analysis, the microsatellite marker order cen-D16S514-D16S421D16S512- D16S3101- D16S3125- D16S518D16S516-D16S504-tel was used with D16S512 and D16S518 being the flanking markers for MCD type $\mathrm{I}^{6}{ }^{10}$ The markers D16S266 and D16S395 were ordered using a YAC (yeast artificial chromosome) contig that we have constructed to span the MCD region (data not shown). The primer sequences for all markers were obtained through the genome database interactive network (see http:// gdbwww.gdb.org/). Amplification of microsatellite repeats was performed by polymerase chain reaction (PCR) using a Hybaid OmniGene thermocycler. ${ }^{11}$ After electrophoresis, gels were stained with SyberGreen (Molecular Probes) and detected by a FluorImager SI (Molecular Dynamics). Haplotype analysis was constructed as previously described. ${ }^{11}$ All pedigree and marker data were fed into a database and managed using the PEDIGENE system. ${ }^{12}$ 


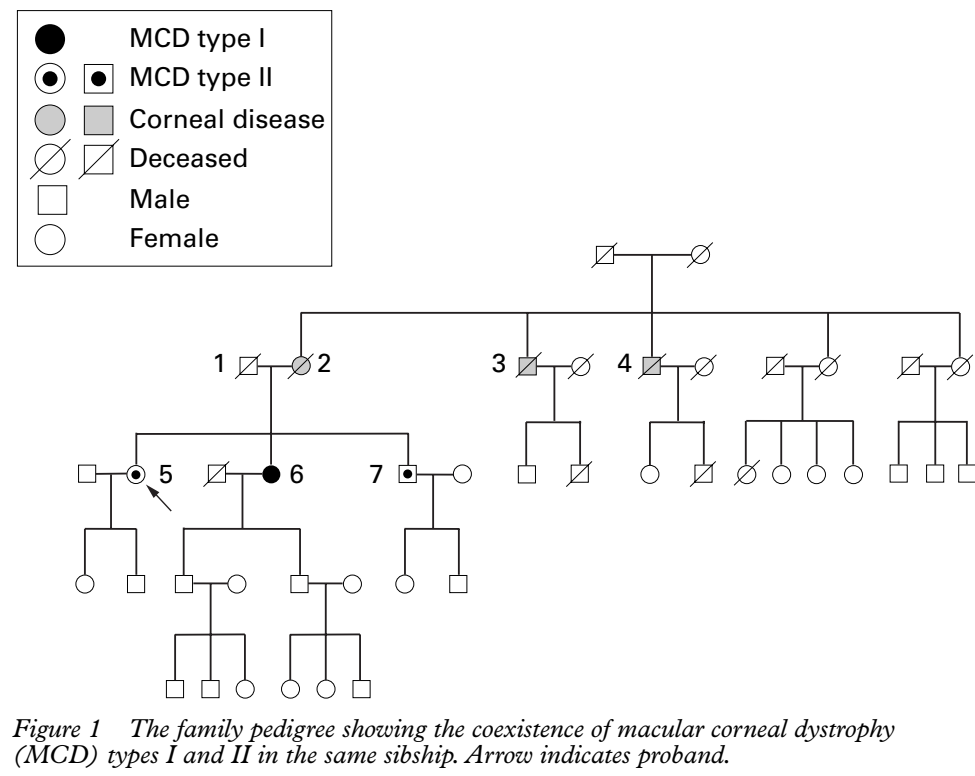

(MCD) types I and II in the same sibship. Arrow indicates proband.

\section{Results}

The pedigree is summarised in Figure 1. Individuals 2,3 , and 4 were born in the late 19 th century and had corneal opacities. Individual 2 died at 78 years of age without having had a corneal transplant. Individual 3 underwent a penetrating keratoplasty, but no material was available for study. The children of individual 2 reported that their mother and uncles had an identical corneal disorder to themselves and were examined by ophthalmologists who confirmed that they all had the identical disorder. However, these ophthalmologists are now dead and owing to the span of time involved, written records confirming these reports are not available. The father (individual 1), who had no symptoms or signs of any corneal diseases, died when he was 77 years old. All three siblings (individuals 5 (aged 86), 6 (aged 80), and 7 (aged 75)) were diagnosed as having MCD. Individuals 5 and 6 have undergone penetrat- ing keratoplasty and the diagnosis of MCD was confirmed histopathologically on the excised corneal tissue. Two of the siblings (5 and 7) were diagnosed as having MCD type II with detectable levels of AgKS in serum. The serum AgKS levels in individuals 5 and 7 were 68 $\mathrm{ng} / \mathrm{ml}$ and $140 \mathrm{ng} / \mathrm{ml}$ respectively (normal individuals without eye or joint disease have serum AgKS levels of $\left.112-617 \mathrm{ng} / \mathrm{ml}^{25}{ }^{13}{ }^{14}\right)$. In a previous study, the glycosaminoglycans $\mathrm{s}^{15}$ and proteoglycans $^{16}$ had been analysed in the corneal tissue from individual 5 (case VC, family 88 in Klintworth and Smith ${ }^{16}$ ). Retrospectively, these biochemical findings were consistent with individual 5 having MCD type II. The serum AgKS level in the third sibling (individual 6) was not above background ( $<9$ $\mathrm{ng} / \mathrm{ml}$ ) and the corneal tissue was negative by immunohistochemical staining; hence individual 6 has MCD type I. There is no known consanguinity in the family. No individual affected with MCD has transmitted MCD or any corneal disease to their offspring, except individual 2 (Fig 1).

Haplotype analysis of individuals 5, 6, and 7 with 10 markers spanning the MCD type I region is shown in Figure 2. Analysis suggests that all three patients inherited a single identical chromosomal haplotype denoted as "A". Both MCD type II siblings (individuals 5 and 7) inherited the same " $B$ " chromosome while their MCD type I sibling (individual 6) inherited a third haplotype "C" (Fig 2). No haplotype inconsistencies were observed for the three siblings in over 100 microsatellites tested.

\section{Discussion}

The pedigree reported here demonstrates the coexistence of MCD types I and II individuals in the same sibship. This extends a previous observation of patients with MCD types I and II appearing in a large inbred pedigree. ${ }^{26}$ Unfortunately, we lack data definitively
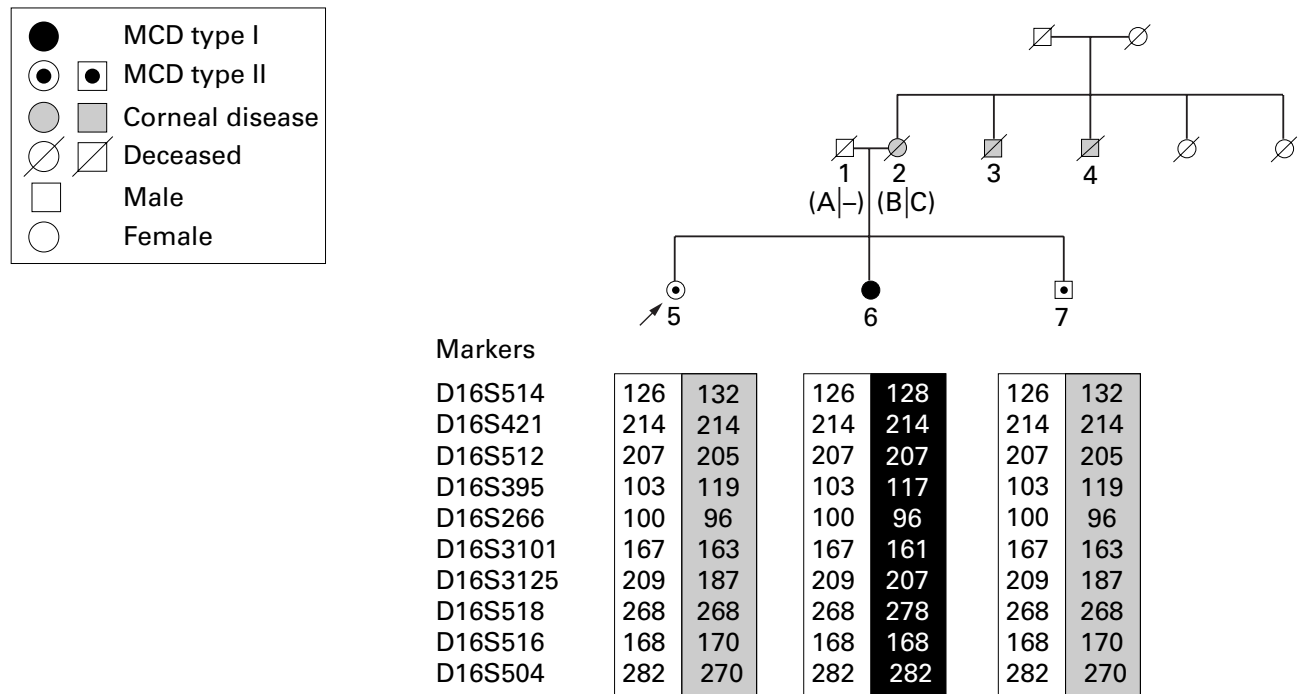

\begin{tabular}{|c|c|}
\hline 126 & 132 \\
214 & 214 \\
207 & 205 \\
103 & 119 \\
100 & 96 \\
167 & 163 \\
209 & 187 \\
268 & 268 \\
168 & 170 \\
282 & 270 \\
\hline A & B
\end{tabular}
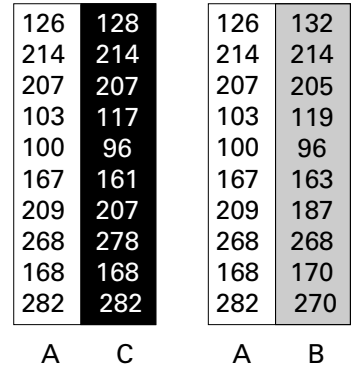

Figure 2 Haplotype analysis of individuals 5, 6, and 7 from Figure 1. A, B, and $C$ denote different chromosomal haplotypes. The names of microsatellite repeat markers are indicated in the left hand column adjacent to the haplotypes. The alleles are designated in terms of molecular weight. Arrow indicates proband. Haplotypes of individuals 1 and 2 are inferred. 
supporting the diagnosis of MCD for the mother (individual 2) and her brothers. Thus, their corneal opacities could represent another entity other than MCD. However, given the presence of the three older siblings (individuals $2,3,4$ ) with corneal opacities, which suggests a genetic disorder, the verbal report of the family and attending ophthalmologists that all affected individuals in this family suffered from the identical disorder, and the pathological confirmation of MCD in the children, the diagnosis of MCD in individual 2 and her siblings would appear extremely likely.

Several possibilities could explain the finding of MCD types I and II in this sibship. We have previously localised the MCD type I gene to chromosome $16 \mathrm{q} 22$, and provided suggestive evidence that MCD type II locus is also linked to the same small region as MCD type $\mathrm{I} .{ }^{6}$ This suggests that the loci are allelic. However, physically close and related genes in this area of chromosome 16 could be involved, as appears to be the case in spinal muscular atrophy on chromosome $5 .{ }^{17}$ However, the finding of both MCD types in this family would require that both parents were double carriers, an extremely unlikely occurrence. Modifier genes, acting on a single MCD gene defect, could also contribute to the differences seen in this family, although the usual consistency of the MCD subtype within families would argue against this. Similarly, this normal intrafamilial homogeneity of MCD type would argue against any significant environmental effect contributing to the differences between MCD types I and II. As the family is not large enough to demonstrate independently significant linkage to chromosome 16 , it is possible this family could represent another yet undescribed MCD locus, either autosomal recessive or autosomal dominant. However, no previous evidence of genetic heterogeneity has been seen in American, Icelandic, and Saudi Arabian MCD families, ${ }^{6} 18$ and no report of autosomal dominant MCD has occurred to date. In addition, if this family represented an autosomal dominant disorder, there were 10 chances (which did not occur) for transmission of the disease to subsequent generations of the family. This would have a likelihood of $1 / 2^{10}$ or only $1 / 1024$, giving strong support that the MCD segregating in this family is due to the known autosomal recessive genes.

Therefore, the most likely explanation for this sibship is that the MCD segregating in this family is due to the known autosomal recessive gene(s) and the two types of MCD are allelic. In this case, the father (individual 1) of these three affected individuals, who was asymptomatic until his death at 77 years of age, would be an MCD carrier. Therefore, he should have only one MCD chromosome to pass to his children. Thus, the " $A$ " haplotype, shared by all the siblings, is most likely the paternal chromosome. Given that MCD is only known as an autosomal recessive disorder, only an affected individual could give two different allele bearing chromosomes. Thus, the " $\mathrm{B}$ " and " $\mathrm{C}$ " haplotypes most probably represent the maternal MCD bearing chromosomes. Non- paternity as an explanation for these two haplotypes is very unlikely, as it would require two different, unrelated MCD carrier fathers. The presence of an affected individual with an autosomal recessive disorder marrying a carrier for the disorder is rare, but not unreported. MCD is not a lethal disorder and should have no significant effect on genetic fitness. In fact, we have seen a similar (affected X carrier) mating occur, with different MCD type I haplotypes, in an autosomal recessive type I MCD family of Icelandic origin. ${ }^{6}$

If MCD types I and II are due to the same genetic origin, what is the mechanism leading to the immunological variation? Unfortunately, while it would have been of great interest, the MCD type of the mother is unknown. If the mother is a compound heterozygote, that would support the hypothesis that MCD types I and II are allelic and their differences might be due to different mutational effects, changing the antigenic site for the AgKS antibody. Certainly, different pathological or clinical manifestations in similar disorders have subsequently turned out to be the result of allelic differences. For example, different mutations of $\alpha$-L-iduronidase produce distinct differences in phenotype between the two mucopolysaccharidoses. $^{19}$

In summary, the data presented here, plus our previous linkage analysis in other MCD type II families, ${ }^{6}$ strongly suggest that MCD types I and II are linked to the same region of chromosome 16 and are likely to be due to allelic manifestations of the same gene. Further collection of additional MCD type II families, or identification of the defect in MCD type I gene, will be needed before a definitive conclusion can be reached concerning the relation between the MCD types I and II.

We would like to thank the family who participated in this study and acknowledge the assistance of the personnel of the Section of Medical Genetics in the Department of Medicine and the Center for Human Genetics at Duke University. The authors thank Zarrín T Brooks for manuscript preparation. This study was supported by grants from the National Institutes of Health, EY08249 (NPL, JB, FL, GKK, JMV), EY00146 (GKK), AG 04736 and AR39239 (EJ-MAT), and NS23360 (JMS, MAP-V).

1 Jonasson F, Johannson JH, Garner Rice NS. Macular corneal dystrophy in Iceland. Eye 1989;3:446-54.

2 Jonasson F, Oshima E, Thonar EJMA, et al. Macular corneal dystrophy in Iceland: a clinical, genealogic, and immunohistochemical study of 28 patients. Ophthalmology 1996; 103:1111-17.

3 Santo RM, Yamaguchi T, Kanai A, Okisaka S, Nakajima A. Clinical and histopathologic features of corneal dystrophies in Japan. Ophthalmology 1995;102:557-67.

4 Yang CJ, SundarRaj N, Thonar EJ, Klintworth GK. Immunohistochemical evidence of heterogeneity in macular cornohistochemical evidence of heterogeneity in macu

5 Klintworth GK, Oshima E, Al-Raihi A, et al. Macular Klintworth GK, Oshima E, Al-Rajhi A, et al. Macular
corneal dystrophy in Saudi Arabia: a review of 56 cases and recognition of a new immunophenotype. Am f Ophthalmol 1997;124:9-18.

6 Vance JM, Jonasson F, Lennon F, et al. Linkage of a gene for macular corneal dystrophy to chromosome 16. Am f Hum Genet 1996;58:757-62.

7 Klintworth GK. Disorders of glycosaminoglycans (mucopolysaccharides) and proteoglycans. In: Garner A, Klintworth GK, eds. Pathobiology of ocular disease: a dynamic approach. 2nd ed. New York: Marcel Dekker, 1994:855-92.

8 Pericak-Vance MA, Yamaoka LH, Haynes CS, et al. Genetic linkage studies in Alzheimer's disease families. Exp Neurol 1988;102:271-9.

9 Thonar EJ, Meyer RF, Dennis RF, et al. Absence of normal keratan sulfate in the blood of patients with macular corneal dystrophy. Am f Ophthalmol 1986;102:561-9.

10 Dib C, Faure S, Fizames C, et al. A comprehensive genetic map of the human genome based on 5,264 microsatellites. Nature 1996;380:152-4. 
11 Ben Othmane K, Hentati F, Lennon F, et al. Linkage of a locus (CMT4A) for autosomal recessive Charcot-MarieTooth disease to chromosome 8q. Hum Mol Genet 1993;2 $1625-8$.

12 Hayes C, Speer MC, Peedin M, et al. PEDIGENE: a comprehensive data management system to facilitate efficient and rapid disease gene mapping. Am f Hum Genet 1995;57:193.

13 Thonar EJ, Lenz ME, Klintworth GK, et al. Quantification of keratan sulfate in blood as a marker of cartilage catabolism. Arthritis Rheum 1985;28:1367-76.

14 Klintworth GK, Meyer R, Dennis R, et al. Macular corneal dystrophy. Lack of keratan sulfate in serum and cornea. Ophthalmic Paediatr Genet 1986;7:139-43.

15 Klintworth GK, Smith CF. Abnormal product of corneal explants from patients with macular corneal dystrophy. $A m$ F Pathol 1980;101:143-58.

16 Klintworth GK, Smith CF. Abnormalities of proteoglycans and glycoproteins synthesized by corneal organ cultures derived from patients with macular corneal dystrophy. Lab Invest 1983;48:603-12.

17 Gilliam TC, Brzustowicz LM, Castilla LH, et al. Genetic homogeneity between acute and chronic forms of spinal muscular atrophy. Nature 1990;345:823-5

18 Wagoner MD, Stone EM, Jabak M, Sheffield VC, Karcioglu ZA. Clinical features of chromosome-16-linked macular corneal dystrophy (MCD). Ophthalmology 1996;103:143.

19 Scott HS, Litjens T, Nelson PV, et al. Identification of mutations in the alpha-L-iduronidase gene (IDUA) that cause Hurler and Scheie syndromes. Am f Hum Genet 1993;53: 973-86. 